\title{
Beehive society: a new concept for observation of China's social-economic transformation
}

\author{
Zhang Jijiao
}

Received: 5 September 2018 / Accepted: 17 September 2018 / Published online: 11 October 2018 (C) The Author(s). 2018 Open Access This article is distributed under the terms of the Creative Commons Attribution 4.0 International License (http://creativecommons.org/licenses/by/4.0/), which permits unrestricted use, distribution, and reproduction in any medium, provided you give appropriate credit to the original author(s) and the source, provide a link to the Creative Commons license, and indicate if changes were made.

\begin{abstract}
The new concept of "Beehive Society" proposed here is corresponding to the term "umbrella society" that was put forward by the author in 2014. This article analyzes basic structure and functions of five types of "beehives" from two categories through two perspectives of employment and management, including chain type, net type beehives of employees, and family, value chain, native ethnic centered beehives of manager. "Beehive society" has no such power or resourcesdue to its folk nature, it can only achieve market space and development opportunity through its own efforts; it is more social and economical rather than being political. The common feature of the various "beehives" in the society is mutual benefit and win-win model; once the "beehives" turn into a group network or ethnic network, it can become economical, social as well as political, and has the power of resources allocation and marketization institutional change.
\end{abstract}

Keywords Beehive society $\cdot$ Social-economic transformation $\cdot$ Structural-function

\section{Introduction}

Since Reform and Opening-up in 1980, China has become the second large economy in the world after thirty-year development; the economic growth has attracted a worldwide attention, and many scholars no matter domestic or abroad are all

\footnotetext{
Z. Jijiao $(\bowtie)$

Department Social Research, Institute of Ethnology and Anthropology, Chinese Academy of Social Sciences, No.6 Blg, No.27, Zhongguancun Nandajie Road, Haidian District, Beijing, China e-mail: zhjijiao@126.com

Z. Jijiao

Council of Commissions, IUAES, Belgium
} 
trying to solve the magic Chinese economy miracle, one of the most concerned issues is how did China transform from planned economy to market economy, that is the market transformation.

After many years exploration, I proposed a new concept of "umbrella society" (Jijiao 2016) to analyze Chinese economical social structure transformation (especially market transformation) in 2014. Shortly, the concept received warmly welcomes by my young colleagues, which encouraged me to explore Chinese economical social structure transformation (especially market transformation) further more, therefore I present companion article of "umbrella society": the investigation of "beehive society".

In this article, we are going to discuss what is common people's role in Chinese huge market transformation? What efforts do they play? Are they beneficiary or impaired party?

\section{Methods/Experimental}

Research hypothesis and analytical framework

To discuss such a complicated economical social structure transformation (especially market transformation) of China, the sole concept of "umbrella society" is apparently insufficient; and based on the consideration of scientific unity of opposites and academic concept matching, I intended to put forward a pair of (two) new concept of Chinese economical social transformation: "umbrella society" to observe "governmental" dominant resource allocation and economic social development, "beehive society" to observe "common people's" self resource allocation and its impact on economic social development.

Governmental dominant economic society is a type of "umbrella society". All these various umbrella structures presented in "governmental dominant" resource allocation and economic social development all over China represent a very obvious character of "umbrella society". There are five levels of "umbrella society", including national level, provincial level, local level, and township level; there are three functions of the umbrella, including "parental love shelter" to affiliated enterprise, "relative shelter" to joint venture, and "friendship shelter" to private enterprise. We call it " $5 \times 3$ umbrella" structure and function.

Common people's economic social life is a type of "beehive society". In the process of transition from planned economy to market economy, the power and privilege shifted from manager to common producer, it allows common people to achieve higher beneficial opportunity and surplus allocation opportunity, which improved the labor enthusiasm; therefore, self-employed, vendor, private owner, blue-collar, white-collar worker, professional manager and freelancer are increasing. We depict this common people's high involvement of market development as "beehive society", in other words, every person are building up their own relationship network-beehives through personal or family's efforts.

In a word, I intend to observe and analyze "official" and "folk" perspectives of Chinese economical social structure transformation through these two (a pair of) 
new concepts of "umbrella society" and "beehive society". This article mainly discusses the common people's self-resource allocation and the involvement of economic social development.

Theoretical basis and general thinking

\section{Theoretical basis}

The theoretical resource and scientific basis of the proposal of the new concept of "umbrella society" and "beehive society" are three economic types by Karl Polanyi (1944), ${ }^{1}$ the pattern of different sequence by Fei Xiaotong $(1948),{ }^{2}$ vertical society by Nakane (1994), ${ }^{3}$ network analyze theory by Granovetter (1973), ${ }^{4}$ market transformation theory by Victor Nee (1989), ${ }^{5}$ social structure transformation theory by Li Peilin, ${ }^{6}$ and social capital theory by James S Coleman (1992). Here we are not going to do further exploration of these theories due to the limited length.

\section{General thinking}

In general idea, there are two hands of resource allocation and economic development. The visible hand of government can be used to analyze the impact of official power on resource allocation and economic social development through a political perspective. The invisible hand of market can be used to analyze the impact of market through an economical perspective. Moreover, Li Peilin points out there are "another invisible hand". The "another invisible hand" theory analyze the function of social structure transformation through a sociological perspective, especially the social relationship and its impact on resource allocation and economical social development.

Through the above theories, we can see that economical social structure transformation (especially market transformation) is realized through resource allocation and economical social development, there are four elements, including power, resource, market space and development opportunity.

\footnotetext{
${ }^{1}$ Karl Polanyi claimed there are three types of human economic production: market economy, redistribution economy, and reciprocal economy. See (Polanyi 1944).

${ }^{2}$ The pattern of different sequence theory: people are self-centered like a little stone throwed into river, and the social relationship is like the waved caused by the stone, more weak more further, the distance of the wave represent the distance of social relations. See (Xiaotong 1948).

${ }^{3}$ Chie Nakane thinks the character of Japanese society is vertical, that is from above to bottom social relations in certain environment. See (Nakane 1994).

${ }^{4}$ Mark Granovetter promoted "social network analyse" method in 1970 basked on embeddedness theory of Polanyi. See (Granovetter 1973).

${ }^{5}$ Victor Nee promoted famous market transformation theory, it represents establishment of new institutionalization theory. See (Nee 1989).

${ }^{6} \mathrm{Li}$ Peilin has developed his "social structure transformation theory" in three articles: "Another invisible hand: social structure transformation", No.5 1992, Chinese Social Sceinces, "Re-discussion on another invisible hand", No.1 1994, "The impact of Chinese social structure transformation on resource allocation", No.1 1995, Chinese Social Sciences.
} 


\section{Empirical investigation of text and materials}

The empirical materials and fieldwork study originate from my fieldwork investigate in recent decade, for exampel Tianjin investigate in 1995, Hainan and Guizhou investigate in 1996, minority group migration in Beijing and Shenzhen investigate in 2001, four cities investigate (Qingdao, Huhehaote, Kunming, Shenzhen) from 2007 to 2008, Hainan investigate from 2011 to 2012, Guizhou and Guangzhou investigate in 2013, etc.

\section{Results and discussion: The structure and function of "beehive society"}

According to above theories, there are four significant elements (power, resource, market space and development opportunity), which impact resource allocation and economical social development, what role or effect do they play in official society (umbrella society) and folk society (beehive society)? In my opinion, "umbrella society" stands for government owns more power and resource; "beehive society" stands for common people achieve more market space and development opportunity through its own efforts although without much power or resources.

Since the Reform-Opening in 1980, there are two major events in urban cities within the market transformation process: the rural immigration and large numbers of private owners and private enterprises in cities.

In this article, I intend to analyze the structure and functions of "beehives" of migrations through employment perspectives, and explore the structure and functions of "beehives" of private owner and private enterprises through management perspectives. It can articulate the structure and functions of Chinese "beehive society" in large degree through these two typical phenomena in Chinese society.

The structure and functions of employment "beehives"

Based on my investigation of urban migrations over decade, the major principle of migrant workers' self-built "beehive" is mutual help; the beehive appears "chain" and "net" two forms (Jijiao 2007, 2009, 2012).

\section{Why do migrant workers need their own "beehive” (social capital)?}

Once leave rural area to unfamiliar urban cities, how does a man earn meal ticket or find somewhere to settle? In economic point of view, one can be settled in cities as long as he owns good physical capacity, certain labor skill or knowledge, and amount of economic capital. But through anthropological or sociological perspectives, besides economic capital, migrant worker must also own certain social capital (social relations) (Bourdieu 1994). ${ }^{7}$

\footnotetext{
${ }^{7}$ French anthropologist Piere Bourdieu was the first one who put forward the concept of Social capital in 1979, he claimed there are three types of capital: economic, social and cultural capital, but he didn't do any further explanation. See (Bourdieu 1994).
} 
Our questionnaire regarding to 207 migrant workers in Beijing in 2001 shows that the introduced by relatives has the highest proportions $(35 \%)$ within all the access of current job, secondly is introduced by friends (25\%), the total is $60 \%$. So to speak, the major access of migrant workers' job relies on their strong tie (relatives or friends) (Granovetter 1973; Granovetter 1974). ${ }^{8}$

In an investigation of Taiwanese invested tool factory in Shenzhen ${ }^{9}$ in 2001, a male Dong minority told us: "I came to Shenzhen once in August (19) 94. I had 1,500 RMB with me, and stayed for one month to look for job, I didn't find any and spent all the money so I went back home. The next year, I came to Shenzhen again, and introduced by fellow-villager, I found this job in Taiwanese invested tool factory. I had been working in the factory floor for one year, and then my boss gave me this job as security man due to my military experiences". ${ }^{10}$ Therefore, physical strength or tough mind is not enough for job-hunting for a person, who came to bustling metropolis from rural village; personal relationship is very much needed. According to the experiences of the above mentioned Dong young man, we can speculate that his military experience and current job qualification may become important employment capital in the future.

Sophisticated social relation is a type of social capital, which plays certain roles in urban employment on certain degree. The relationship is not only mutual connection, but also mutual responsibility; one can be able to received help or resources needed due to this tight connection and clear responsibility. This human relationship is like a bank account, the credit can be used any time needed (human relationship credit) (Coleman 1992). ${ }^{11}$

\section{Three stages of migrant workers "beehive" construction}

According to our observation and investigation in Hainan, Guizhou, Beijing, Shenzhen, Guangzhou over decade from 1996 to 2013, the structure and function of migrant worker's beehive appears three development stages:

\section{A, The first stages: "advance force" of individual migrant employer}

This is first step or attempting period of making a life away from home. For example, during my investigation in southeast of Guizhou province in 1996, I found out that some local young people were agitated by the propaganda of the Reform and Opening-up in Shenzhen Special economic zone who were not satisfied by the

\footnotetext{
${ }^{8}$ Mark Granovetter divided human relationships into strong tie and weak tie. It is based on interaction frequency, emotional strength, intimacy degree and reciprocal exchange. Strong tie exist inside group, weak tie exist between groups. See (Granovetter 1973; Granovetter 1974).

${ }^{9}$ Shenzhen is the very first special zone in Reform-and-Opening up period, international metropolitan HongKong is a crossed the shore. Manufacture industry was very well developed in 1999, there were millions of factories in the city, which attracted many young people come to work there.

${ }^{10}$ Material resource: interview in Shenzhen Guangdong, in 2001.

${ }^{11}$ James S. Coleman is an important scholar who analyzed the social capital theory for the first time. He defined social capital as productive element for certain goals, and it is embedded inside the social structure based on trustworthy relation resource. See (Coleman 1992).
} 
current situation, and came to Shenzhen to make a life very recklessly. These fearless forgoers do not have any human relationships in big cities except the courage of "dare to be the first crab eater" and young blood, most of them started with very humble job and fight alone seeking for survival and development opportunities. As one can imagine how difficult and risky it can be when a single person comes to struggle in the big city alone without any available social capital. Therefore, the successful cases of individual migrant employment must be very rare.

\section{B, The second stage: "chain type" group migrant employment}

The individual forgoers' struggle alone is over at this stage; certain social relationship had been built up in their explorations and accumulations. Based on the forgoers' exploitation and accumulation for many years, their family members, relatives (sometimes including friends, fellow-villagers) not only can receive employment or business information, but also be able to migrant to the city based on this strong tie, forming the "chain type" migrant employment. For example, during my investigation in Haikou in 1996, I met twelve male Miao peasants from Taijiang County of Guizhou province at a bus station. Their 28-year old leader named LXL had come to work in a farm in Changjiang County where is rural western area of Hainan three or 4 years ago. Last year (1995), LXL had brought two of his brother and two of his relatives (five in total) came to work in Changjiang together. This time, he brought more friends, eleven followers in total. They all have junior high school education, aged from 18 to 30 . They had traveled thousands of kilometers from rural village of Guizhou to Guangdong province and to the destination of Changjiang County of Hainan. ${ }^{12}$ Under the strong tie of the forgoers, the followers shaped a migrant work chain, which we call it "leading" migrant employment. They had accesses to social relationship, employment information and experiences, due to the accumulated social capital and experiences of the forgoers, therefore the risk or cost for the second stage of "chain type" or "leading" group migrant employment has dropped dramatically.

\section{$\mathrm{C}$, The third stage: "net type" group migrant employment}

Based on the "chain type" or "leading" group migrant employment of the second stage, it developed into the third stage of migrant employment, which has developed into a network underpinned by group "net". For example, according to our investigation in 2001, there were 122 Dong people and 3 Miao people working in a Taiwanese invested tool factory in Shenzhen. Most of them were from Tianzhu County of Guizhou Province, the rest were from Xinhuang County of Hunan Province.These more than 100 people work in the same place was attributed by the "network" mutual help from lot of people. Behind every single migrant workers back, there was not only a chain of consanguinity or affinity, but also other human relations based on them, like neighbors, classmates, friends, fellow-villagers,

\footnotetext{
${ }^{12}$ My investigation in Haikou Hainan in 1996 (Jijiao 2003).
} 
colleagues, peers or bosses. This horizontal human relation network are originated or based on vertical human resource chain, not only forgoers but also followers can reach to the human relation network as the support for making a life in big cities.

\section{The structure and functions of migrant employee's "beehive”}

Power, resource, market space and development opportunity are the four important elements for resource allocation and economical social development in the process of economical social structure transformation of marketization; while government and administrative officials owns relatively more power and economic resource, how do common people achieve market space or development opportunities with very few political power and economic resource? For the poor-and-blank migrant workers, the most feasible way is to use his inborn resource (like consanguinity and affinity relations) and traditional principle (like family ethic of mutual help). These are the social foundation and principle foundation for the construction of group chain type "beehive" and group network "beehive" followed.

Observing the whole society, how does folk "beehive" society locate it self and play its role in governmental "umbrella society"? Government builds the stage and capital plays the role in the process of market transformation, it is impossible for powerless migrant worker to build up his own "beehive" over night and the cost and risk are relatively high for the individual forgers, in short, it is very unlikely for migrant workers to build up "beehive" in the first stage. Till the second stage, these forgoers become queen bee and bring worker bees (relatives and friends) come to work in the cities, and it is qualified for them to build up their own "beehives". In this leading type of group migrant employment, members of the "chain type" group build up "beehive" led by the leader, and it based on certain human relations of the leader's relatives, family members, etc. In the third stage, the network of migrant workers is becoming wider and wider, the range has gone beyond the consanguinity or affinity and it is qualified to become net type "beehive". In the third stage of net type, the social capital of "net type" not only owns instinctive consanguinity and affinity relations, but also expanded to acquired relationships, like neighbors, classmates, friends, fellow-villagers, colleagues, peers, and bosses, etc. With much wider social relations of net type of "beehive" compare to "chain type", its social capital becomes more powerful. This expanding "beehive" built up by migrant workers is exactly following the theory of "pattern of different sequence", therefore it can accumulate and share more and more resources inside. In a word, the main principle of migrant workers self-built "beehive" is mutual help; it has two types of "chain type" and "web type". Folk "beehive" society becomes supplement part of official "umbrella" society; they exist to side by side and play a part together.

Why is it necessary for migrant workers to build up a shared mutual-helped construction of "beehives"? In The Great Transformation, Karl Polanyi claimed there are three types of economic productions: market economy, redistribution economy and reciprocity economy (Polanyi 1944). Thus, what are the relationship between these three types of economic production and three development stages (forgoers individual employment, "chain type" group employment, and "net type" group 
employment) of migrant workers "beehives"? For migrant workers who left rural village enter into big cities' strange environment of equivalent transaction of market economy and/or political redistribution economy, it means they have been divorced from reciprocal nature economy system through economic system point of view. To obtain living space in this strong economic mode or economic system of big cities, migrant workers must use the existing reciprocal method brought from their hometown, find some footholds in the blank space in the process of transformation from reciprocal economy to market economy, or embed into the marginal space of institutionalized redistribution economy and market economy through chain type and web type "beehive" in the group.

So to speak, the breakthrough of old system in the market transformation begins with individual breakout and followed by the unremitting efforts of "beehive" groups, they are both non institutional behaviors, but will become institutionalized market economy system eventually. In other word, the establishment of new system roots in individual informal efforts or trials, it is a transformation from informal to formal institutionalization; moreover, the transformation of system experiences a whole process from individual to group and finally the whole society, it is a debugging process from original nature to institutional nature.

The structure and functions of management "beehives"

Based on many years' investigation and observation, I consider there are three types of management "beehives", including family-centered mutual benefit network, value chain-centered win-win cooperation network and ethnic group-centered mutual benefit and win-win network.

Here are some outrageous misunderstandings of Chinese economical marketization transformation:

\section{Family "beehive": Family-centered mutual benefit network}

In popular point of view, family is a place where spouse raise their offspring and live together. Economists usually think that economical market transformation is highly degreed business practices, which is not necessary rely on family. In China, there are more and more economists ignore economy functions of family. Although, in sociologists, anthropologists and ethnologists' point of view, family not only owns important social functions but also economic roles. William J Goode has pointed out, "People usually forget that family is also a economic unit although it's not a agriculture unit anymore". ${ }^{13}$ Gary S Becker also mentioned, "in all societies including modern market economic society, family still takes responsibilities of more than half of the economic activities" (Becker 1987).

\section{A, Family business is trailbreaker of the city-township marketization}

\footnotetext{
${ }^{13}$ Goode 1986, Family, translated by Wei Zhangling, Beijing: Social Sciences Academic Press.
} 
During the investigation in Qionghai of Hainan Province in 1996, I learnt that since early 1980, individual industrial and commercial households appear in the process of urbanization due to the policy that allows coexistence of multiple economic components. There are 2836 households of 3449 people in 1983; it grows into 5746 households of 77,007 people in 1990. Why does family business become the trailbreaker in city-township marketization process? I think there are several political, economic and social reasons as followed:

Firstly, self-employed household emerged as the time requires. On one hand, family business is an economic unit where mandatory plan cannot be implemented in planned economy system, and it is also the weakest sector of planned economy system, has naturally become the earliest breakthrough in urban marketization. On the other hand, family business is the most oppressed economy unit before the Reform-and-Opening up, and no matter urban private business or rural family business they were all nearly extinct. ${ }^{14}$ The longer family business has been depressed, the stronger the revival desires become, and they grow up very rapidly like the spring bamboo shoots after the rain.

Secondly, in the early stage of Reform-and Opening up, the first sprout of marketization and reformation can only exist in the industries, which doesn't affect the extant economic benefit or institutional structures due to the very powerful planned economic system. Therefore, we can see that individual industrial and commercial household and private service industry has achieved rapid and well development under the spontaneous effort of individuals and households.

Thirdly, one major objective reason of family business's revival is that state owned or collective commerce declined due to the mismanagement. During early stage of marketization, public business lost its monopoly while market opened up. On one hand, public business couldn't adapt to the market competition, on the other hand they become less and less competitive because of the rigid and floated organization and high costs. ${ }^{15}$

Fourthly, the social basis of family business is "home-style" management. I have seen a lot of examples of "store run by couples". In the center market ${ }^{16}$ and

\footnotetext{
${ }^{14}$ In 1953, guideline towards private industry was "utilization, limitation, and reformation", till 1956, there were 612 private stores and 777 employment had been reformed, with 179,037 Yuan shared capital. In 1958 , the private and public stores were all in cooperated into state business, individual dealer were forced to closed up. In 1961, a few private businesses were allowed during economic readjustment. From 1963 to 1964, unlicensed traders were cleaned out, and issue contemporary business license. During "culture revolution", private business was almost extinct. Resources from: Qionghai County Chorography, P 305, 1995, Qionghai Chorography edition Committee, Guangdong Technology Press.

${ }^{15}$ For instance, there were 52 accounting units in Qionghai state business system, and 32 of them had deficit of 2.484 million Yuan in total, the whole city supply and sale deficit was 5.124 million Yuan, pending deficit was 5.7 million Yuan, deferred expenses was 1.77 million Yuan. Resource from: Qionghai County Chorography, P 302-304, 1995, Qionghai Chorography edition Committee, Guangdong Technology Press.

${ }^{16}$ Center market was located in the center area of Jiaji town, it was built up by raising fund. According to different types of berth the price ranged from 4500 Yuan to 5000 Yuan each household. The money served as raising fund, and you may rent one berth, the interests of the money can be served as rental from 1989 to 1997. The rental can be re-discussed after that. With more than one million raising fund and Qionghai Industry and Commerce Bureau funded two million, they established the market with three floors, sales dry sea food, fruits, daily grocery, meat, vegetables on the first floor, clothing on the second, and offices on the third.
} 
markets along the street in Jiaji County, we've witnessed the routine structure of family shops: the shop is on the first floor, and the family members live on the upstairs, thus the economy of shop and sociality of the family become coexisted unrepeatable two aspects of a whole. In the household, there are clear labor division and tacit cooperation between the spouse, and it conforms to the local customers that husband engages in social activities like drinking tea with business partners, while wife is in charge of receiving customers in the store. Man stays in to receive customers while woman goes back home to cook during mealtime. Li Peilin claimed that family is not only social activity structure but also economic activity structure which is quite similar to factory or company as economic structure to enterprise; and the ethical norms of the family is the management regulations of the family business, just like the factory or company's bureaucracy organizational management norms as the whole enterprise's management norm (Peilin 1995). My investigation of Beijing in 2001 shows that the management of small family business is usually as followed: the husband works as the ownership or charger, the wife take in charge of the finance, and the offspring or young relatives work as employees. There are normally two to three or seven to eight workers in total, and very rarely there are more than ten workers. In small family enterprise, husband or wife owns the absolute authority as head of the house, and their relations play the dominant role inside the small enterprises human relations, the relation's of family members or employment are all subordinate to the spouse relation. Inside the small enterprise, all the events of daily life, income, distribution or consumes are arranged by the owner/head of the household (Jijiao 2004a).

\section{B, Family commerce and altruism ethic}

In general economic point of view, every person is pursuing maximization of self-interests as selfish economic individual. But in non-economic disciplines like sociology or anthropology, the hypothetic of selfish human character is untenable. Economist usually separates the economic activities from social activities. But in reality, especially in family business it is very difficult to separate them. Family business management is not only economic activities, which seeks benefit or continuity of family property, but also a social activities that pursuit love and happiness, and the owner/head of the household will do the cost and benefit calculations based on both above aspects. Why there is obvious "altruistic" tendency in family business? My study in Qionghai of Hainan Province shows that all the efforts and hardworking of the owner are all for the whole family to have a better life, for the children to have bright future, these are all his motive force or spiritual foundation.

The final goals of the parents who are also managers of the private business are not only self-interests, social status or family life but also to create a better living or studying conditions for the children, to help them achieve more compare to their parents. I have confront of such similar thought and experiences in the interview of several owners, for example clothing retailer H.Zh.A has very hard experiences of struggling in big cities away from their hometown. He told me, "The major income are used for kid's education". The theory of family altruism had been firstly 
proposed by Becker in his book A Treatise on the Family. The owner uses the income of family business, which is also major economic resource to invest in the education or health of the family members (Becker 1987). Family can live out individual, and to be continuous many generations. Every generation's start point of this life in the family is results of last generation's effort and accumulation. It is very shameful for parents if they failed to build up a good foundation for the children. Therefore, we give the altruism family ethic ("great devotion of parents") a relatively good explanation through a sociological perspective.

The principle of resource allocation in family business is mutual benefits, while the principle of market resource allocation is "benefit pursuit" (Peilin 1995). Thus, we can see that individual family business are all competing with each other pursuing self-interests in the market, while owner and family members are pursuing mutual-interests based on mutual benefit principles inside the family. Therefore, altruism is one of the "nature principles" of family or group life.

\section{$\mathrm{C}$, Trade cost of family business and "beehive" relative network ${ }^{17}$}

Based on my investigation over decades (Jijiao 1998, 2001; Jijiang and Yanzhong 2015), I found out that family members or relatives (sometimes good friends, classmates with long friendship) are more willing to offer help to the beginners.

Why do relatives or friends will to offer selfless help (like venture capital fund) to entrepreneurs who have not succeeded and don't have much of social prestige or wealth?

Chinese American anthropologist Francis L K Hsu claimed interdependence is Chinese people's basic behavior pattern. Especially in kinship relations, the interdependence is very obvious. Every single person's duty and responsibilities are all very clear that every endowment requires payback (even though it is long after that) (Hsu 1990). Different from government or enterprises, resource allocation of family business depend on family ethic principles and kinship relations that are non-economic, and non-institutionalize rules like kinship relation or family ethic principles are playing a leading role. Centered by certain head of the household or person who has high prestige, every single person are all connected to the kinship network and play certain roles in the economic activities of the family or household, it forms a set of beehive like devices, which is based on the principle of "earning money together" making joint efforts and sharing the benefit.

In this "beehive" where everyone are surviving and flourishing together, people are offering help or information of many aspects like capital, supply, human resource and customers through a invisible network shared by "family" or "insiders". In the field of industry, relatives or friends usually tend to enter into the same or similar industry, which is more convenient for mutual help. For example, I had interviewed a clothing retailer named $\mathrm{H} \mathrm{Zh} \mathrm{A}$ in Qionghai. ${ }^{18} \mathrm{He}$ claimed that he's

\footnotetext{
${ }^{17}$ Kinship network, or kinship relations, it includes family, lineage, affinity or consanguinity relationships. In some degree, friends, neighborhood can be seen as the extension of kinship relationship. It is a multiple long-lasting social relathions.
} 
only familiar with clothing retail compare to other different business, and he doesn't intend to expand nor change his career. In my opinion, $\mathrm{H} \mathrm{Zh} \mathrm{A} \mathrm{doesn't} \mathrm{want} \mathrm{to}$ undermine current stable situation by expansion or transformation, because it is risky to loss current relative mutual help network which is very difficult to regain. The mutual help of kinship network within family economic activities represent like an exchange, which is a transaction combined with economic and social exchange, it is long-term exchange and social economic relationship contains family affection.

Before the marketization and regulations grow mature, the "beehive" resource allocation based on kinship network has its rationality, which thrives family business. Family centered kinship relationships of family business is equivalent to kinship network "beehive", it follows a set of family ethic rules where bargain or agreement are unnecessary. These customary behavior regulation and ethics has been handed down from generation to generation, which save a great deal of organization, management and trading costs.

\section{Value chain type of "beehive": Win-win network centered by value chain}

Here I analyze the win-win network (value chain type of "beehive") based on the empirical material of family industry investigation in Qionghai. ${ }^{19}$

Since late Qing dynasty, various handcrafts workshops in Qionghai are all over the place, including more than thirty industries like pottery, papermaking, leather, ironware, sugar and shipbuilding, etc. After the establishment of new China, there are 37 family factories whose output value reached 1.04 million Yuan. From 1954 to 1956, family handcraft workshop had downsized 420 employees after the process of public-private joint management. Gexu County picked 22 family workshops from collective industry to work as individual enterprise that take whole responsibility of loss or benefit. From 1966 to 1976 (cultural revolution period), family industry had been cut off as "tail of capitalism". Family industry had recovered and developed dramatically after the Reform-and Opening up period in 1980. Till 1984, there were 4440 family factories in the whole city, with 7141 employees and 25.47 million Yuan output value. ${ }^{20}$ Private family factories were running their machines day and night trying to cut one small piece of "cake" from the market while lots of state-owned enterprises and factories were declining, losing benefit or even shutting down. The private family industry motivated by individuals or families holding a non-hostile resistance altitude ${ }^{21}$ broke the resistance of rigid

\footnotetext{
${ }^{18}$ Since 1980, H Zh A started his small business, which was the very first private business in Jiaji County. His start-up fund was seven or eight hundreds Yuan, and borrowed some money from relatives. It sells daily grocery and so on. After 1 year, he started cloth business, start-up fund was two thousand Yuan, and also had borrowed some extra. He always borrowed money after that, and return the money back after a while without any agreement in writing, depending only on credit. He always returned money very willingly after borrowed them.

19"Family industry" contains two meanings, one is factory owned by family, the other one is the family members' main labor (technic, management, finance). See (Jijiao 1999a, 1999b).

${ }^{20}$ Qionghai County Chorography, P 241, 1995, Qionghai Chorography edition Committee, Guangdong Technology Press.
} 
planned-economic system and developed into small but competitive new element of the market, which promotes the transformation of market and roles.

One of the major characters and functions of family factories is that: it expands the ethic roles of kinship relationships from inner family to networks between supplier, retailer and wholesaler; on the other way around, the supplier, retailer and wholesaler will follow the ethic and moral regulations within the family factory. It forms a value-chain between family factory, supplier, retailer, and wholesaler, ${ }^{22}$ and it forms a win-win network based on value-chain. The four parties of family factory, supplier, retailer, and wholesaler build up a "beehive" together, which is called value-chain "beehive". The owner of the family factory is the "queen bee" of the value-chain "beehive".

In 1996, there was a head of a family factory in Qionghai who had told me, "Our products are all over the whole island, they are mainly distributed through local retailers and also other sale channels. Our factory has never signed any contract with our distributors; we are doing business together based on trustworthiness. Altruism is also egoism, it will build up a nice and cozy environment for yourself". 23

Family industry expands the code of conduct for kinship networks into a even large range compared to family business. The head of the family factory is like the queen bee, which has built up a mutual trust network between the supplier, retailer and wholesaler based on value-chain. For family factory, this gradually established value-chain "beehive" is a relatively stable network of production, supplement and sales. It is not only a reliable network for purchasing, producing, management and sales but also a win-win operation mode between the supplier, retailer and wholesaler.

\section{Ethnic "beehive": Mutual benefit network based on minority groups}

Minority groups migrant from boarder ethnic communities to cities where is highly heterogeneous, will they become shattered groups? The investigation in cities of Sichuan shows that Yi people still hold very strong lineage concept even after they left rural village migrated into big cities. In Yi society, people belong to the same lineage help each other in social and economic activities. Two different lineages caught into fight, they always protect their own members. While facing other ethnic groups (like Han), no matter how the situation is all the lineages are all stick up together.

\footnotetext{
${ }^{21}$ Philip Mattera mentioned that, people resist current economic regulation with his or her own power, it was a very complicated fight back form, it is non-organized and sometimes not even hostile to the regulation. See (Mattera 1985).

${ }^{22}$ According to Porter's value-chain theory, I think that market competition not only happen between enterprises, but also inside the enterprises. The operation flow becomes a real chain, makes them connected to each other, and also makes them adapted to capital, transportation and information flow, makes the supplement, production and sale become a "value-chain", this is the real problem faced by value-chain management. See (Jijiao 2001).

${ }^{23}$ Resource is from my interview of owner of noodle factory in Qionghai Hainan Province in 1996. The factory was established in 1992, the brand name is "lede". The main productions were curved egg yolk noodle and wide yolk noodle. The factory was rated as Excellent Township Enterprises of Qionghai in 1994, and Excellent Provincial Enterprises of Hainan in 1994. The production line was the 18th line in Hainan. The factory maintains the high quality in very competitive market, and also lower prices when necessary. Although the movement of the market, the factory was developing very well recently.
} 
A, For individual enterprise, the management and employment have ethnic character

In our investigation of Beijing ethnic private enterprises in 2001, we found that due to the ethnic custom or language they usually employ people who belong to their minority groups. Fro example, in some ethnic characteristic restaurant (Yi, Uygur, Mongolia, Tibet, or Miao), it is usually more persuasive when native people recommend dishes to customers. A very typical example was, several years ago there was a Tengelitala restaurant in west of Beijing, they owned a performance group called "Beijing Tengelitala troup" with tens of Inner Mongolia dancers and singers. ${ }^{24}$ Recently, there is an Aobao (Mongolia tent) party, employed several Mongolia actors hosting Erdos topic weddings. These are very typical examples of organized and large minority groups' employment in Beijing.

My investigation of Beijing in 2001 also shows that the dependence degree of minority on relatives and friends are relatively higher than Han people. For those minority group people who has been grown up in boarder area and are very strange to urban life, migrate into city and engage in non-agricultural job is a huge event. If there is no one to offer accommodation, food or job, it is very unlikely for him or her to leave hometown recklessly. They dare to leave hometown and migrant to big cities only if there are some relatives or friends who can be relied on. ${ }^{25}$

B, For minority group, the management has ethnic character

For minority entrepreneurs who are originated from boarder areas, the ethnic characteristic business is their major paths. These ethnic people start their own business alone or with partners, it not only increases the survival and development opportunity but also brings unique ethnic cultural to the city life. "Ethnic character" is an important condition for market access and also a significant competitive advantage. The "ethnic character" shows very distinct personality, which attracts customer's attention. These characteristic entrepreneurs exactly fill in the "blank" or "gap" of market's diversification demand.

I have obtained some first-hand materials based on investigation of several cities in China from 2007 to 2008, and analyzed the elements that effects the transformation of ethnic groups' "economic cultural types". ${ }^{26}$ Some minority groups like Korean people from Qingdao, Mongolian people from Hohhot and Hui people from Kunming appeared transformation from "original ecology style" to "market style" after they migrate into city economic cultural

\footnotetext{
${ }^{24}$ I have interviewed several managers, ethnic dancers and singers in Tenggelitala restaurant for many times from 2001 to 2002, and have been watched marvelous show.

${ }^{25}$ During a conversation with a deputy manager of a company, she analyzed that, "Why do the employees want to work at a company with very low salary but accommodation, because it settles them, gives them place to eat and sleep, so they can focus on the job". There was a restaurant near my home, and I can always see young workers come out of a basement dorm to go to work, their hard working spirit always inspire me.
} 
Table 1 Migrate minority groups' social relationship network ${ }^{\mathrm{a}}$

\begin{tabular}{lll}
\hline & Relationship & Strength Grade \\
\hline Type 1 & Family & The highest \\
Type 2 & Kinship & High \\
Type 3 & Geographic and occupation & High or low \\
Type 4 & New occupation and friends & Low \\
\hline
\end{tabular}

aThe table is based on "pattern of different sequence" theory of Fei Xiaotong. The network is centered by kinship relationship and extended to many levels of intimate relations, and further extended to the boarder of minority groups community, and then extended to classmate, friends, fellow-villagers, etc. The basic principle is mutual help and trust, and owes each other favors. See (Xiaotong 1985)

environment. To be specifically, the economic cultural type of Qingdao Korean migration is "dependent-transplantation style", Hohhot Mongolian migration is "innovation-transplantation style", and Kunming Hui migration is "half innovation-half integration style". For example, a large number of Mongolian people left pastoral area to the city of Hohhot, apparently the environments are quite different but still belong to the same ethnic culture circle. Thus, based on the large background of Mongolian culture, Mongolian people engage in food and beverage service or ethnic handcrafts sales once they left pastoral area migrant into city, which promotes urbanization and marketization of grassland productions. On one hand, it forms relatively centralized business aggregation zone in Hohhot, on the other hand, it connects pastoral area with city area, immigration with emigration very naturally. Generally speaking, Mongolian migration and ethnic entrepreneurs are constructing a new type of economic culture in city: its one end leads to pastoral area, the other end leads to outsider market (urban markets inside the Inner Mongolia Autonomous Region and even more larger domestic and abroad markets). These ethnic enterprises become a "connector" between city and pastoral area, modern and tradition, industry and nomad. It is very ethnic distinctively in management, social identity and cultural identity.

\section{C, Social foundation of ethnic "beehive"}

In the investigation of Korean, Mongolian, Tibetan, and Dai people's small family enterprises (restaurant, hair salon or beauty salon) in Beijing in 2001, I found out that most of the employees belong to the same minority groups of ethnic employers, and most of them are relatives like husband, wife, children, etc. There are many of Korean private enterprises, ${ }^{27}$ which is also more typical. The examples

\footnotetext{
${ }^{26}$ Economic cultural type was a classification concept promoted by two Russian scholars in 1950 to classify the world nationalities beyond linguistic genealogy. The according Chinese academic results was the article named Chinese economic cultural types, written by Lin Yaohua and Чебоксаров, H.Н. in August 1958. The 30,000-character article was published in Russia in961, and had been translated into Japanese and published in Assays on Ethnology in East Asia from 1965 to 1967. Till 1985, it had been published in China. See (Yaohua 1985).
} 
represent the situation of employment based on family or kinship relations for the Korean entrepreneurs while they migrant from hometown to Beijing.

Therefor, the subject who is using the social relationship as social capital is not employee but the entrepreneur and managers; they are like the queen bee of the ethnic "beehive". From Table 1 we can see that, the social foundation that underpin ethnic "beehive" is minority group's basic social relations. "Type 1: family relation" is the most basic relationship network and social capital for entrepreneurship and management of family business; "type 2: Kinship relation" is major relation network and social capital for the employment. In family enterprises, no matter which relationship, the functional regulation principle is family ethic roles. "Type 3: geography and occupation relation" network is sometime strong and sometimes weak, "type 4: new occupation and friends" network are usually weak. Type 3 and type 4 are not strong enough to be used without further development.

On the surface, the social basis of ethnic "beehive" and general "beehive" are quite similar that they are all based on social network. Actually, they are different. Minority group's "beehive" is ethnic characteristic, and the social network is available within minority group, it is native mutual benefit network.

\section{Structure and functions of manager "beehive"}

There are three types of manager "beehive": family "beehive", value-chain "beehive", and ethnic "beehive" according to above analyses, and the basic principle is mutual benefit and win-win.

The growth of these private ethnic enterprises does not only depend on economic ability but also social cultural background. Private ethnic enterprise and manager have ethnic resources like distinct ethnic culture, language, value concept, kinship and community relations (Aldrich and Waldinger 1990), These distinct characters help them to build up various "beehives" to obtain entrepreneurship capital, low costs labor, business credit and develop them into business and management activities after they left home (Jijiao 2004b). More and more successful ethnic enterprises and mangers are gathering together and become ethnic enterprise group based on human relations of various family "beehives" and value-chain "beehives".

Normally, "beehive" network has strong economic and social characters, but weak political character. But, once it developed into an ethnic enterprise group, then the ethnic "beehive" network may achieve a new character-political character besides social and economic characters. The leader of ethnic enterprise group may be able to connect official government with folk appeals. Therefore, it will appear connections between ethnic enterprise leader and government agencies, certain ethnic entrepreneur and government officials. In general, the political character of ethnic "beehive" cannot be ignored, so to speak besides resource allocation functions the ethnic "beehive" also has power for promoting marketization regulation transformation.

\footnotetext{
${ }^{27}$ In vestigation material of Beijing in 2001, there were 29 cases in the neighborhood of Minzu University of Weigongcun area, 19 cases nearby Beijing language and culture university, and 39 cases nearby xinyuanli and maizidian in Chaoyang district.
} 


\section{Conclusion}

The new concept of "beehive society" is corresponding to "umbrella society" proposed by the author in 2014 .

\section{A general explanation and describe of "beehive society"}

Why do we metaphor common people and their life as "bee" and "beehive"?

Firstly, common people are industrious just like "bee" untiringly gathers honey, they depend on their bare hands and hard workings fighting for life no matter in hometown working as peasants or come to city. Secondly, common people don't own powerful political capital like "government officials" do nor as wealthy as successful business men, but they can earn wealth and development through employment or entrepreneurship due to the more and more market space and development opportunities after the Reform-and-Opening up, just like industrious bees gathering honey day and night and harvest the most sweet results. Common people won't achieve market opportunities without marketization. Thirdly, every single person are connected to each other in the giant social structures, the relationship is just like the construction of "beehive" (relationship or cirle). Most of the time, these "beehives" are centralized by a certain family or lineage. The mutual benefit network of certain relationship is convenient for mutual help and share of market transformation dividend. Fourthly, every invisible relation or network is different. But they also have something in common: there is usually one "queen bee" leading many "worker bees" to gather honey and bring them back to build up their own "beehive". Fifthly, the various "grass-root" network and relationship circle (beehive) built up spontaneously by common people usually do not own much of political power nor social resources, but it can help fighting for market space and development opportunities basked on traditional moral rules and customized regulations, and to build up folk mechanism of market resource allocation and economic social development. Sixthly, common people's relationship network and circles (beehive) are invisible, but they are still part of non-official economic social construction. "Beehive society" is one of the characters of economic social structures.

\section{Major conclusion}

In this article, I analyzed basic structure and functions of five types of "beehive" through employment and management perspective. To be specific, there are chain-type and net-type "beehive" of employees, and family, value-chain and ethnic "beehive" of managers. I call it structure and functions of " $2 \times 5$ beehive". "Beehive" relationship is not related to primary or secondary group of social relation, but also involved in urban society and commercial society; it is not only related to social exchange but also related to human economic character. These various relation circle or networks have something in common that is the existence of queen bee (leader). The leader is like the "King without grown", who serves as certain leading or directing functions inside the circle. They could be the head of a household, elder with high prestige or sometimes very successful businessman. 
In recent decade, I have been thinking about the relationship between market transformation and resource allocation in China (Jijiao 1999a, 1999b). If the structure of Chinese economic society is dualistic: the "big tradition" of government dominated "umbrella society" and the "little tradition" of folk "beehive society", then whether they are separated or connected in some degree? Folk "beehive society" don't own many of power or resource, but they can achieve market space and development through its own efforts, therefore it normally has more economic and social characters but less political character. Once the various "beehives" in the society grow bigger and bigger and finally become group, regional network ${ }^{28}$ or ethnic network, there will be a new function of political character besides the original social and economic character. So to speak, as long as "beehives" become a group or ethnic, they will obtain economic, social and political characters, which promote the resource allocation and marketization regulation transformation. Therefore, certain size of group "beehive" or minority groups may build up connections with government agencies, which promote the marketization regulation transformation. In short, different from the above-to-bottom resource allocation of "umbrella society", the bottom-to-above behavior of folk society must rely on group or ethnic "beehive" social structure to be functional in resource allocation and regulation transformation.

\section{Authors' contributions}

The author read and approved the final manuscript.

\section{Ethics approval and consent to participate}

Not applicable.

\section{Consent for publication}

Not applicable.

\section{Competing interests}

The author declares that he has no competing interests.

\section{Publisher's Note}

Springer Nature remains neutral with regard to jurisdictional claims in published maps and institutional affiliations.

\footnotetext{
${ }^{28}$ For example, businessman from Zhejiang Province is called "Zhe businessman" for short, which is entrepreneur group with powerful economic strength and political influence in China nowadays. See (Jijiao 2013).
} 


\section{References}

Aldrich, Howard, and Roger Waldinger. 1990. "Ethnicity and entrepreneurship", in Annual Review of Sociology. Vol. 16, 111-135.

Becker, Gary. 1987. A treatise on the family, translated by Peng Songjian, 227. Beijing: Huaxia publishing house.

Bourdieu, Pierre. 1994. Distinction: A social critique of the Judgement of taste. Translated by Richard Nice: Roultedge Press.

Coleman, James. 1992. Foundations of Social Theory, translated by Deng fang, chapter 12, P330-P354. Beijing: Social Sciences Academic Press.

Goode, William. 1986. Family, translated by Wei Zhangling. Beijing: Social Sciences Academic Press.

Granovetter, Mark. 1973. The strength of weak ties. American Journal of Sociology 78: 1360-1380 1974, Getting a Jab: A Study of Contacts and Careers, University of Chicago Press.

Granovetter, Mark. 1974. Getting a jab: A study of contacts and careers. Chicago: University of Chicago Press.

Hsu, Francis. 1990. Clan Caste and Club, translated by Xue gang. Vol. 277. Bejing: Huaxia Publishing House.

Jijiao, Zhang. 1998. 'The Resource Allocation Function of Family and Kinship Network in the Process of Marketization_- Taking the Family Business of Han Nationality in Qionghai City of Hainan as an Example', Journal of the Ideological Frontier (5):45-50.

Jijiao, Zhang. 1999a. Informal regulations of marketization. Vol. 94. Beijing: Cultural Relics Press.

Jijiao, Zhang, 1999b, "Informal regulation, resource allocation and institutional change", No. 1, Journal of the Ideological Frontier.

Jijiao, Zhang. 2001. Value-chain management: Optimize business process and comprehensive competitions of enterprises, 4. Beijing: China Price Press.

Jijiao, Zhang. 2003. In "Ethnic Minority Labor Out-migrants from Guizhou Provinces their Impacts on Snding Areas”, in China's minorities on the move: selected cases, ed. Robyn Iredale, Naran Bilik, and Fei Guo, 148. New York: M. E. Sharpe, Inc.

Jijiao, Zhang. 2004a. Adaptation of the city: The employment and entrepreneurship of migrations, P91-P92. Beijing: The Commercial Press.

Jijiao, Zhang. 2004b. Urban adaptation: Employment and entrepreneurship of migrations. Vol. 91. Beijing: The Commercial Press.

Jijiao, Zhang, 2007, "Migrants' Social Network Used in Seeking Employment in Urban Areas", in Urbanization and Multi-Ethnic Society. Buddhadeb Chaudhuri and Sumita Chaudhuri, India: Inter-India Publications,. 427-466.

Jijiao, Zhang. 2009. "The orientation of urban migrants' social network: A comparative survey on six minorities in the cities of China", in Chinese History and Society. Vol. 35, 127-139. Berlin: Berliner China-Hefte.

Jijiao, Zhang, 2012, "Migrant Social Networks: ethnic Minorities in the cities of china", in Wind over Water: Migration in an East Asian Context. David Haines, Keiko Yamanaka, and Shinji Yamashita. New York: Berghahn Books, Chapter 3, .47-59.

Jijiao, Zhang. 2013. "New entrepreneur community study: Analyses of the generation and characters of Zhe businessman through enterprise anthropological perspective”, Enterprise and urban development: Not all economic issues, 123-132. Beijing: Intellectual property publishing house.

Jijiao, Zhang. 2016. Umbrella society: A new concept for observations of Chinese economical social structure transformation. International Journal of Business Anthropology (by Cambridge Scholars Publishing) 6 (2): 83-102.

Jijiao, Zhang, and Yanzhong, Wang. 2015. Economic and Social Survey Report of China's Ethnic Regions (Kaili). Beijing: China Social Science Press.

Mattera, Philip. 1985. Off the books: The Rise or the Underground Economy, 129. New York: Sr. Martin's Press.

Nakane, Chie. 1994. Human relations in vertical society, translated by Chen Chengze. Beijing: The Commercial Press.

Nee, Victor. 1989. A theory of market transition: From redistribution to market, American sociological review. Vol. 54.

Peilin, Li. 1995. Chinese social economic transformation: sociological analyses of economic system reform, 85. Haerbin: Heilongjiang People's publishing house.

Polanyi, Karl. 1944. The great transformation. New York: Farrar \& Rinehart.

Xiaotong, Fei. 1948. From the soil: The foundation of Chinese society. Shanghai: Shanghai Observation.

Xiaotong, Fei. 1985. From the soil: The foundation of Chinese society, 21-28. Beijing: SDX joint publishing company.

Yaohua, Lin. 1985. Ethnology study, 104-142. Beijing: Social Sciences Academy Press. 